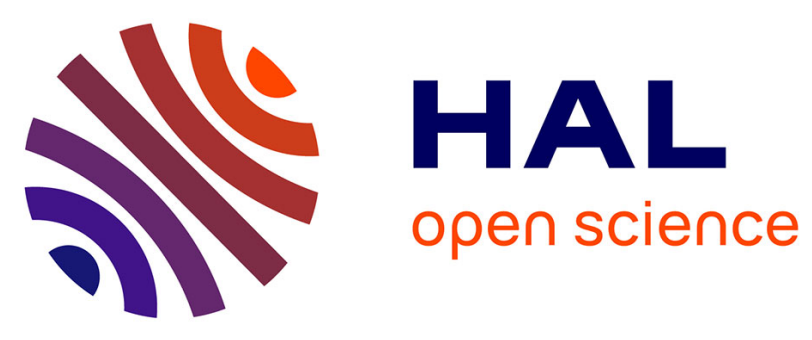

\title{
A mass-selective ion transfer line coupled with a uniform supersonic flow for studying ion-molecule reactions at low temperatures
}

Baptiste Joalland, Nour Jamal-Eddine, D. Papanastasiou, A. Lekkas, Sophie Carles, Ludovic Biennier

\section{To cite this version:}

Baptiste Joalland, Nour Jamal-Eddine, D. Papanastasiou, A. Lekkas, Sophie Carles, et al.. A massselective ion transfer line coupled with a uniform supersonic flow for studying ion-molecule reactions at low temperatures. Journal of Chemical Physics, 2019, 150 (16), pp.164201. 10.1063/1.5086386 . hal-02149464

\section{HAL Id: hal-02149464 \\ https://hal-univ-rennes1.archives-ouvertes.fr/hal-02149464}

Submitted on 1 Jul 2019

HAL is a multi-disciplinary open access archive for the deposit and dissemination of scientific research documents, whether they are published or not. The documents may come from teaching and research institutions in France or abroad, or from public or private research centers.
L'archive ouverte pluridisciplinaire HAL, est destinée au dépôt et à la diffusion de documents scientifiques de niveau recherche, publiés ou non, émanant des établissements d'enseignement et de recherche français ou étrangers, des laboratoires publics ou privés. 


\title{
A mass-selective ion transfer line coupled with a uniform supersonic flow for studying ion-molecule reactions at low temperatures
}

\author{
B. Joalland, ${ }^{1, a)}$ N. Jamal-Eddine, ${ }^{1}$ D. Papanastasiou, ${ }^{2}$ A. Lekkas, ${ }^{2}$ S. Carles,${ }^{1}$ and L. Biennier ${ }^{1, b)}$ \\ 1) Univ Rennes, CNRS, IPR (Institut de Physique de Rennes) - UMR 6251, F-35000 Rennes, \\ France \\ ${ }^{2)}$ Fasmatech Science $\&$ Technology SA, TESPA Lefkippos, NCSR Demokritos, 15310 Athens, \\ Greece
}

(Dated: 1 April 2019)

A new approach based on the uniform supersonic flow technique - a cold, thermalized de Laval expansion offering the advantage of performing experiments with condensable species - has been developed to study ion-molecule reactions at low temperatures. It employs a mass-selective radio frequency transfer line to capture and select ions from an adaptable ionization source and to inject the selected ions in the core of the supersonic expansion where rate coefficients and product branching can be measured from room temperature down to $\sim 15 \mathrm{~K}$. The transfer line incorporates segmented ion guides combining quadrupolar and octapolar field orders to maximize transmission through the differential apertures and the large pressure gradients encountered between the ionization source $(\sim$ mbar $)$, the quadrupole mass filter $\left(\sim 10^{-5} \mathrm{mbar}\right)$, and the de Laval expansion $(\sim$ mbar $)$. All components were designed to enable the injection of cations and anions of virtually any $\mathrm{m} / \mathrm{z}$ ratio up to 200 at near ground potential, allowing for a precise control over the momentum and thermalization of the ions in the flow. The kinetics and branching ratios of a selection of reactions have been examined to validate the approach. The technique will be instrumental in providing new insight on the reactivity of polyatomic ions and molecular cluster ions in astrophysical and planetary environments.

\section{INTRODUCTION}

Ions are detected in trace amounts in astrophysical environments, ranging from interstellar clouds and starforming regions to protoplanetary disks and circumstellar envelopes. $^{1-4}$ Nearly 30 positive ions have been discovered in space to date, mostly through radio-astronomy. This inventory has recently been enriched by the detection of negative ions. The six anions identified so far all belong to the chemical families of polyynes and cyanopolyynes. ${ }^{5-10}$ In spite of their rarity, ions play a major role in the chemistry of astrophysical environments because they are highly reactive. In fact, most ionmolecule reactions proceed with large rate coefficients at room temperature and below due to the strong attractive forces between the ion and the permanent or induced dipole of the neutral partner. Ion-molecule reactions have thus been invoked as formation pathways for complex organic molecules. ${ }^{11}$ Molecular ions have also been found to be the key drivers of chemical processes in cold planetary atmospheres such as Titan's, where the Cassini Huygens probe has revealed the presence of a variety of large and positive ions (up to $1000 \mathrm{~m} / \mathrm{q}$ ), ${ }^{12,13}$ and significant amounts of even larger negative ions (up to 13800 $m / q) .{ }^{14}$ These observations have led to the proposition of a new chemical scheme in which molecular growth starts at high altitude through ion-molecule reactions, leading to a rapid mass gain of macromolecules that ultimately generates aerosol seeds. ${ }^{15,16}$

\footnotetext{
a) Electronic mail: joallandb@gmail.com; Current address: Department of Chemistry, Wayne State University, Detroit (MI), USA

b) Electronic mail: ludovic.biennier@univ-rennes1.fr
}

The formation and destruction pathways of most interstellar and atmospheric ions under the cold conditions prevalent in these environments are still elusive, ${ }^{2-4}$ although considerable efforts have been devoted to develop new experimental methods. In this realm, a key achievement remains the buffer gas cooling experiments with the 22-pole ion trap of D. Gerlich. ${ }^{17}$ With an appropriate combination of trapping time and neutral density, the large and nearly field-free volume of this high-order multipole ion trap is suitable for measuring the lowtemperature kinetics of slow reactions such as radiative association. ${ }^{18-20}$ On the other hand, the T. Softley group has demonstrated the possibility for reaching the ultracold regime with collision energies below the $\mathrm{mK}$ by introducing velocity-selected neutrals in a linear Paul trap where laser-cooled ions were confined. ${ }^{21,22}$ Latterly, Paul traps have been coupled to time-of-flight mass spectrometry to make simultaneous measurements on multiple exit channels. ${ }^{23,24}$ Nevertheless, ion traps are in general prone to condensation issues at low temperatures, which often limit their applications to light neutral co-reactants.

The uniform supersonic flow (USF) or CRESU technique, originally developed by J.B. Marquette and B.R. Rowe to explore ion-molecule reactions at low temperatures, ${ }^{25}$ offers the advantage of a wall-less experiment where no condensation occurs in the scrutinized medium. The technique relies on de Laval nozzles designed by solving the nonlinear Navier-Stokes equations for viscous fluids. From these nozzles emerge a dense (typically $10^{16}-10^{18} \mathrm{~cm}^{-3}$ ) isentropic core in which temperature, density, and translational velocity are uniform for several tenths of centimeters. Under these highly controlled thermodynamic conditions, ions, neutrals, radicals, and clusters are thermalized by inelastic collisions 
with the carrier gas and travel for several hundreds of microseconds in the course of which their reactivity can be monitored with diverse spectroscopic and mass spectrometry probes. ${ }^{26-32}$ Today this technique has reached a high degree of transferability and versatility owing to the development of different strategies to obtain stable, non-turbulent pulsed flows that reduce considerably the necessary pumping capacities, ${ }^{33-35}$ and to the design of temperature-tunable de Laval nozzles. ${ }^{36}$

Our interest in the reactivity of molecular ions in astrophysical and planetary media has led us to report recently on the rate coefficients and branching ratios of reactions of $\mathrm{CN}^{-} / \mathrm{C}_{3} \mathrm{~N}^{-}$ions with the polar molecules $\mathrm{HCOOH}$ and $\mathrm{HC}_{3} \mathrm{~N}$ over the [36-300] $\mathrm{K}$ temperature range. ${ }^{37-39}$ To our knowledge, it was the first time the kinetics of bimolecular reactions involving a tetraatomic anion was revealed at low temperatures. The experiments were performed with continuous USFs and an electron gun generating a high energy and high current $(200 \mu \mathrm{A})$ electron beam crossing the flow transversely. Under this configuration, the production of ions is limited by the availability and properties of the precursors, which must exhibit a sufficient vapor pressure at room temperature $(>10$ mbar) and be commercially available or synthesizable. Cations are generated through charge transfer with the ionized carrier gas $\left(\mathrm{Ar}^{+}, \mathrm{He}^{+}, \mathrm{N}_{2}{ }^{+}\right)$. In most cases, the process induces heavy fragmentation and makes the kinetic analysis complex and the determination of branching ratios difficult, if not impossible. For anions, which are produced by dissociative electron attachment, ${ }^{40}$ the cross-section for the low-energy electrons generated by the ionization of the buffer gas must be non-null and the process must also lead dominantly to the targeted ion. Taken together, these conditions put strong constraints on the variety of ions that can be studied in the laboratory.

An alternative approach consists in injecting massselected ions issued from an external ion source into the core of the uniform supersonic flow as in the first CRESU set-up. ${ }^{25}$ Similarly to the selected ion flow tube (SIFT) method, ${ }^{41}$ only the primary ion of interest and the neutral co-reactant are present in the reaction zone. The method was validated with the study of the ion-molecule reactions $\mathrm{He}^{+}+\mathrm{N}_{2}, \mathrm{O}_{2}{ }^{+}+\mathrm{CH}_{4}$, and $\mathrm{N}^{+}+\mathrm{H}_{2}$ at temperatures of 20 and $70 \mathrm{~K}$. The drawback was that the ion source was incorporated within the de Laval nozzle generating the USF, which had to be changed every time the reaction was investigated at a different temperature. Later on, Speck et al. developed a pulsed ion source coupled to a CRESU reaction chamber and independent of the nozzle design, although this time the source was not selective in mass. ${ }^{42}$

To overcome these limitations, we have developed a new approach based on a mass-selective ion transfer line that aims at achieving the same versatility than the SIFT technique while taking advantage of the latest developments in radio frequency (rf) ion guiding. The design of the new experiment is presented in Sec. II and char-

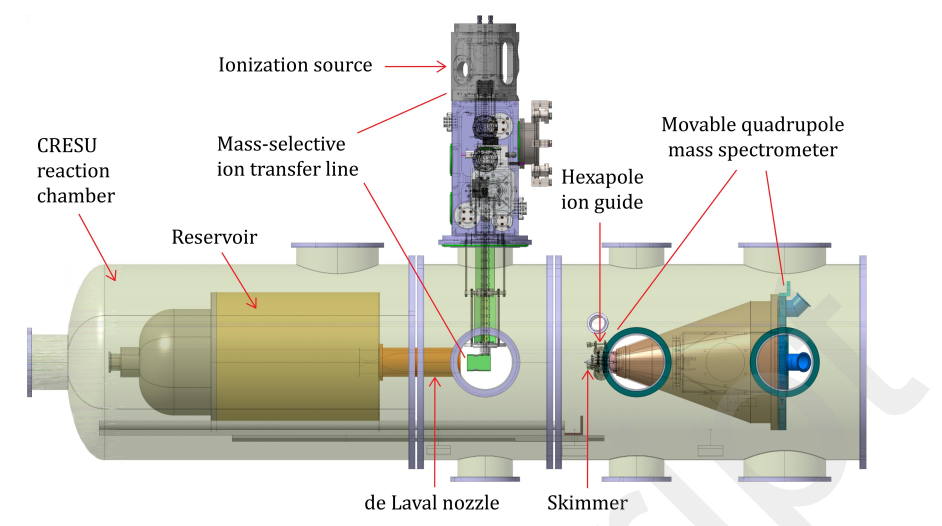

FIG. 1. The CRESU reaction chamber incorporating the new mass-selective ion transfer line. A movable quadrupole mass spectrometer updated with a skimmer / hexapole ion guide combination is used for monitoring ions in the de Laval expansion. High-capacity roots pumps (>20000 $\left.\mathrm{m}^{3} / \mathrm{h}\right)$ maintain the desired pressure (0.1-2.0 mbar) in the reaction chamber.

acterized in Sec. III. A number of rate coefficients and branching ratios of benchmark reactions were measured and are discussed in Sec. IV. Concluding remarks and future directions are given in Sec. V.

\section{DESIGN}

An overview of the CRESU reaction chamber with the new mass-selective ion transfer line is shown in Fig. 1. The monitoring of ions along the de Laval expansion is performed by a quadrupole mass spectrometer (QMS) housed in a differentially-pumped conical chamber. The detection chamber, mounted on a positioncontrolled translating stage, was modified to incorporate a rf hexapole ion guide combined with a molecular beam skimmer to enhance sampling efficiency of reactant and product ions.

\section{A. Mass-selective ion transfer line}

The mass-selective ion transfer line is shown in Fig. 2, along with the operating pressure regimes of the different ion optical components. A hollow cathode discharge source operated at $\sim 1$ mbar is depicted although a variety of ionization sources can easily be implemented. Ions formed near the boundaries of the plasma are transferred through a rf ion funnel and injected into a low pressure region $\left(<10^{-2}\right.$ mbar $)$ accommodating a segmented $\mathrm{rf}$ ion guide (labeled 1, $5 \times 2 \mathrm{~cm}$ segments). Ions are subsequently introduced into a quadrupole mass filter operated at $\sim 10^{-5}$ mbar with an optimal kinetic energy of $10 \mathrm{eV}$. In detection mode a mass spectrum is generated using an off-axis electron multiplier. In transmission mode ions are transferred into a second, elongated rf ion guide (labeled 2, $20 \times 2 \mathrm{~cm}$ segments) operated at $\sim 10^{-2}$ 


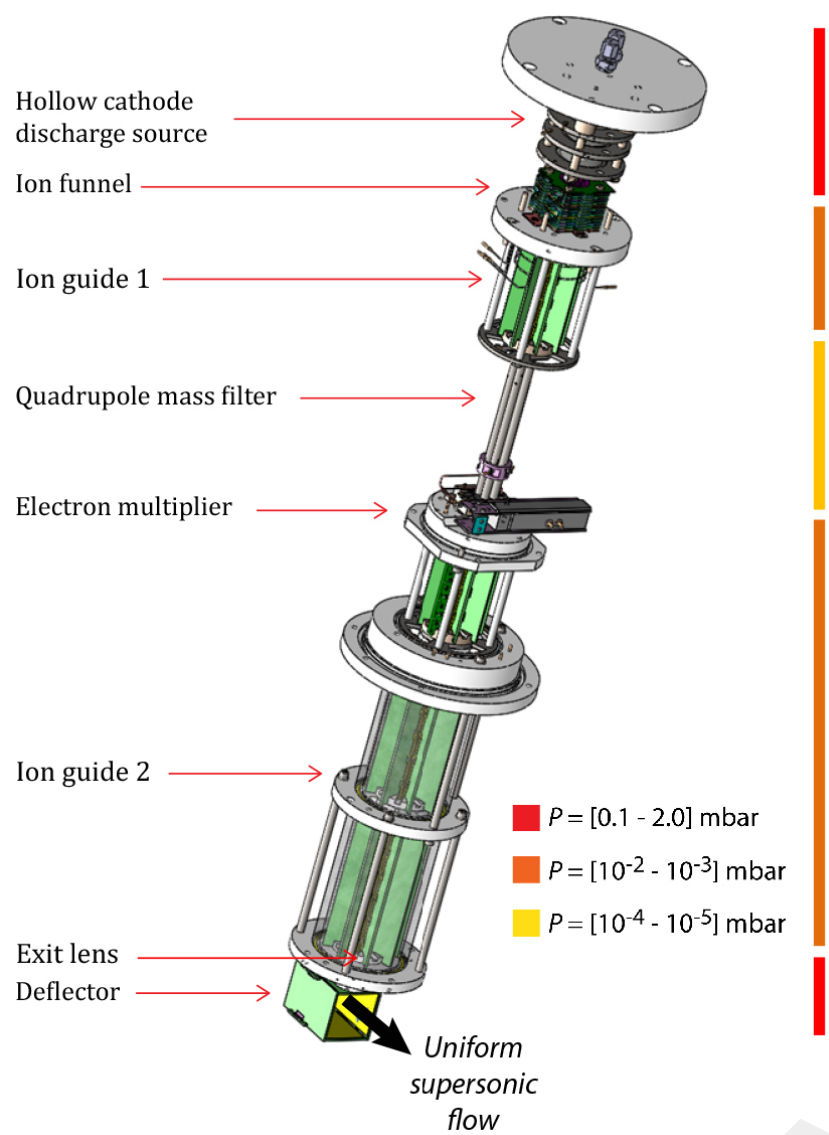

FIG. 2. 3D CAD model of the mass-selective ion transfer line along with pressure regions.

mbar and injected into the reaction chamber through a $2 \mathrm{~mm}$ aperture - the exit lens - located near the tip of the de Laval nozzle. The voltage applied to a deflector plate, which is positioned $5 \mathrm{~cm}$ from the exit lens, is adjusted to inseminate the isentropic core of the transversal uniform supersonic flow with the mass-selected ions.

Douglas et al. studied collisional focusing effects in rf quadrupoles and showed that, provided a low initial ion kinetic energy $(1-30 \mathrm{eV})$, the ion transmission through a small aperture at the exit of a quadrupole increases as the pressure increases to reach a maximum near $10^{-2}$ mbar, i.e. very close to the pressure conditions of ion guides 1 and $2 .{ }^{43}$ In addition, collisional focusing was found to be accompanied by significant losses of axial kinetic energy, which is one of the purposes of the new ion transfer line. The ion optics assembly is indeed designed to maintain the exit lens at near ground potential to allow for a precise manipulation of the mass-selected ions in the injection region and their rapid thermalization in the flow (see schematic and potentials in Fig. 3). This required to modify the rf generator driving the quadrupole mass filter (Cyionics) so that it can operate at a floating potential $( \pm 500 \mathrm{~V})$. Both ion guides are designed with an octapolar field at the entrance (three segments) to

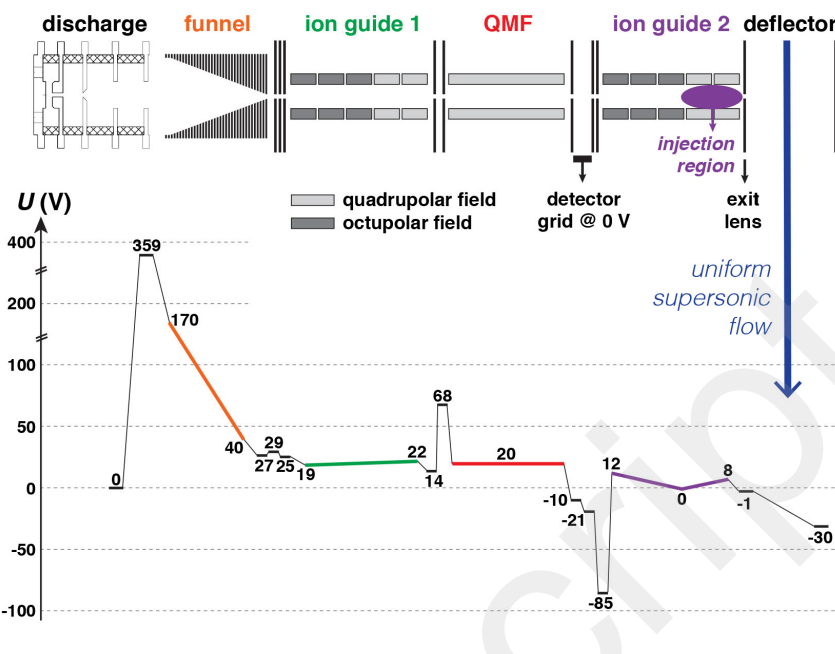

FIG. 3. Schematic of the ion optics assembly and optimized potentials for injecting $\mathrm{Ar}^{+}$ions in a uniform supersonic flow. Lens potentials are in black and floating potentials of rf components are in color. Injection region is highlighted in purple.

enhance phase space acceptance and a quadrupolar field at the exit to compress ions radially and thus maintain high transmission through narrow apertures. A weak dc gradient is applied across the segments to counteract collisional cooling and maximize transmission. ${ }^{44}$

All dc and rf potentials applied to the ion transfer line are controlled electronically through our own computer interface. Bipolar dc power supply units (PSU) are employed so that the transfer line can be operated in positive and negative ion mode. A single rf PSU delivering a $2 \mathrm{MHz}$ sinusoidal waveform is used to drive the funnel, the ion guides, and the hexapole integrated upstream the detection QMS (see Sec. II C), while independent dc PSUs are employed to control all static potentials applied to the lens electrodes and to establish the axial dc gradients across the ion guides. In terms of vacuum requirements, the ionization source is backed by a rotary pump (Edwards, $28 \mathrm{~m}^{3} / \mathrm{h}$ ) and its pressure adjusted with a butterfly valve. Two turbomolecular pumps are used to maintain the ion guides at intermediate pressure (Oerlikon, $360 \mathrm{~L} / \mathrm{s}$ and Edwards, $70 \mathrm{~L} / \mathrm{s}$ ) and combined with another one (Edwards, $70 \mathrm{~L} / \mathrm{s}$ ) to differentially pump the quadrupole mass filter.

\section{B. Ion trajectory simulations}

Ion trajectories were simulated in realistic low-pressure gas flows to better understand the role of scattering on the ion transmission in the injection region (see Figs. 3 and 4). Computations for the diffusive jet formed at the exit lens by the USF carrier gas in the direction of ion guide $\mathbf{2}$ were performed using the direct simulation Monte Carlo solver ${ }^{45}$ implemented in OpenFOAM. Inlet boundary conditions were obtained by introducing a 


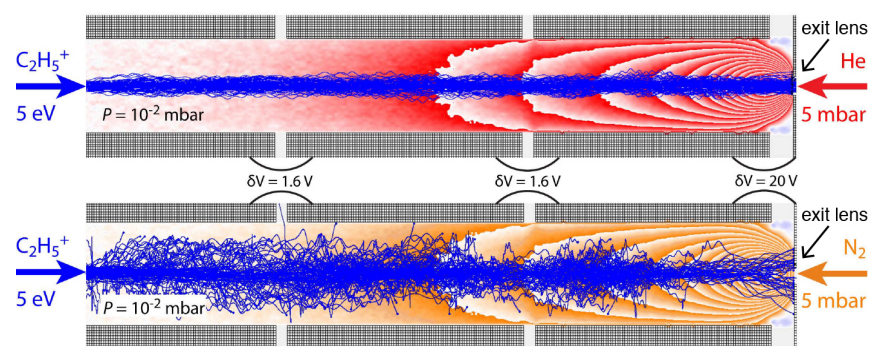

FIG. 4. Simulated trajectories of $\mathrm{C}_{2} \mathrm{H}_{5}{ }^{+}$ions in the injection region (last three segments of ion guide $\mathbf{2}$ / exit lens) superimposed on velocity contours of $50 \mathrm{~m} / \mathrm{s}$ for $\mathrm{He}$ (red) and $\mathrm{N}_{2}$ (orange) buffer gases with maximum axial and radial speeds of $620 \mathrm{~m} / \mathrm{s}$ and $360 \mathrm{~m} / \mathrm{s}$, respectively.

high pressure inlet boundary at the exit lens and solving the expansion flow along the axis of the ion guide maintained at $10^{-2}$ mbar. The quadrupole geometry consisted of three $20 \mathrm{~mm}$ long equally spaced $(1 \mathrm{~mm})$ segments. The inscribed radius of the ion guide was $4 \mathrm{~mm}$ and the $10^{-2}$ mbar pressure boundary was defined at a $7.5 \mathrm{~mm}$ radius with reference to the ion optical axis. The postprocessed solution for the flow field was introduced in SIMION where ion optical tracing was carried out using a velocity dependent ion-molecule collision model based on ion mobility experimental data. ${ }^{46}$

Two examples of ion trajectory simulations are shown in Fig. 4, where $\mathrm{C}_{2} \mathrm{H}_{5}+$ ions with kinetic energy of $5 \mathrm{eV}$ are transferred by a weak dc gradient $(1.6 \mathrm{~V}$ per segment) and accelerated into the higher pressure region by a $20 \mathrm{~V}$ difference applied to the $2 \mathrm{~mm}$ exit lens. Velocity contours are used to visualize the diffusive jet in the rf ion guide. In the case of an He buffer gas, the ion transmission is $\sim 60 \%$, while in the case of $\mathrm{N}_{2}$ the scattering is much more significant and the transmission falls down to $\sim 5 \%$. The simulations indicate that increasing the potential difference between the final segment and the differential aperture improves ion transmission only marginally: an ion transmission of $\sim 80 \%$ is achieved for a potential difference of $100 \mathrm{~V}$ with the He diffusive jet. Significant losses due to scattering with He were also observed for low-mass ions ( $\leq 10 \mathrm{amu})$.

\section{Ion sampling and detection}

Under the previous configuration with the electron beam as ion source, ${ }^{37-39}$ the ion content in the USF was sampled by an aperture of $80 \mu \mathrm{m}$ at the tip of the cone detection chamber, while the diameter of a typical isentropic core ranges from $5 \mathrm{~mm}$ to $1 \mathrm{~cm}$. A large distance $(66 \mathrm{~mm})$ between the tip of the cone and the entrance lens of the QMS led to significant losses of ions. The sensitivity of the detection scheme had therefore to be improved because the ion current generated by the new transfer line lies in the $[0.1-1] \mathrm{nA}$ range, i.e. three orders of magnitude lower than with the electron beam. To this end the combination of a molecular beam skimmer with an hexapole ion guide filling the gap between the cone tip and the QMS was designed. Under CRESU operating conditions, the pressure in the ion guide is maintained in the $\left[10^{-2}-10^{-3}\right]$ mbar range through a connection to the roots pumping system of the reaction chamber. The voltage applied to the hexapole is decomposed into a dc component of a few $\mathrm{V}$ and a rf component of a few hundreds of V. A 10x larger skimmer (Beam Dynamics 0.8 $\mathrm{mm}$ i.d.), gold plated to protect from corrosion, was installed to increase ion transmission by $100 x$. The new ion sampler was tested with a HCDS directly mounted in front of the detection scheme. The skimmer was polarized by a fraction of $\mathrm{V}$. The application of a potential of $200 \mathrm{~V} \mathrm{rf}$ amplitude to the hexapole resulted in a further $15 \mathrm{x}$ enhancement. The skimmer / hexapole ion guide combination therefore enables us to circumvent in its entirety the lower ion currents generated by the massselective ion transfer line.

\section{CHARACTERIZATION}

We report here on proof-of-concept measurements for the injection of $\mathrm{Ar}^{+}$ions. An $\mathrm{Ar} / \mathrm{He}$ mixture is admitted into the ionization source and the glow discharge $(360 \mathrm{~V}-$ $1 \mathrm{~mA}$ ) projects ions through the ion funnel, from which they are captured by the first ion guide before reaching the quadrupole mass filter. The presence of $\mathrm{Ar}^{+}, \mathrm{ArH}^{+}$ as well as traces of $\mathrm{H}_{2} \mathrm{O}^{+}, \mathrm{H}_{3} \mathrm{O}^{+}$, and $\mathrm{N}_{2}{ }^{+}$ions was detected, as shown in the inset of Fig. $5 . \mathrm{Ar}^{+}$ions were selected and all the dc potentials of the transfer line were adjusted to maximize the ion currents measured on the exit lens, the deflector, and the skimmer of the detection chamber with a picoammeter. The optimized potentials for injection at near ground potential are shown in Fig. 3.

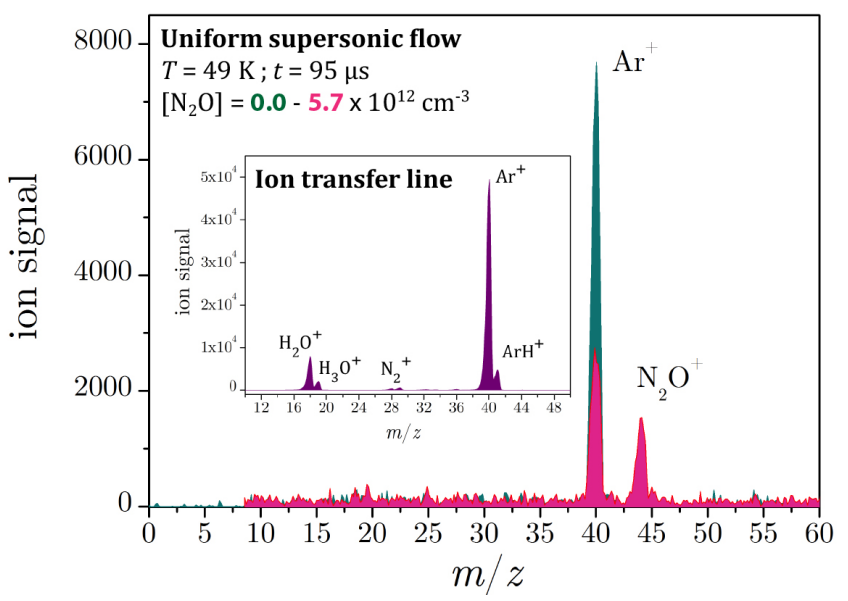

FIG. 5. Mass spectra in a uniform supersonic flow at $49 \mathrm{~K}$ inseminated by mass-selected $\mathrm{Ar}^{+}$ions after a reaction time of $95 \mu$ s in absence (green) / presence (pink) of $\mathrm{N}_{2} \mathrm{O}$. Inset: mass spectrum in the ion transfer line for an $\mathrm{Ar} / \mathrm{He}$ plasma. 

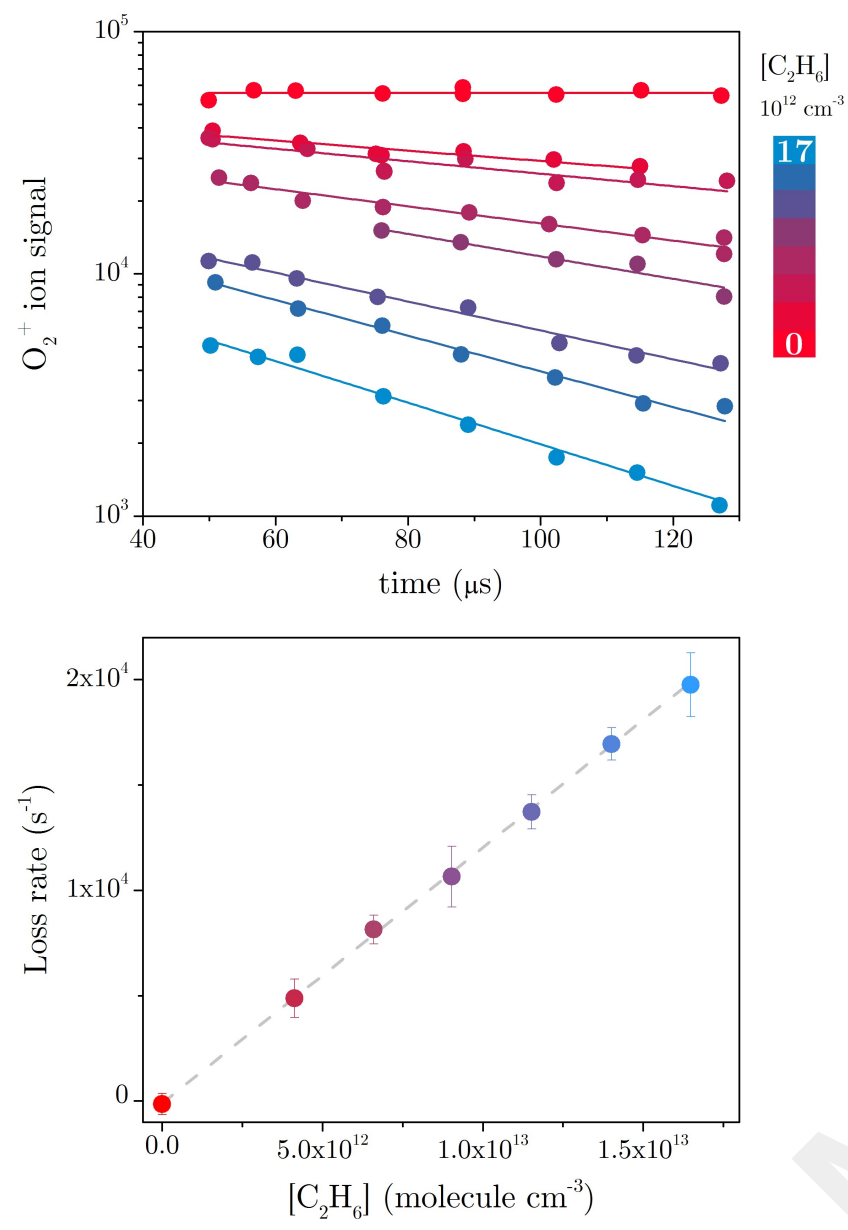

FIG. 6. $\mathrm{O}_{2}{ }^{+}$ion signal at $49 \mathrm{~K}$ as a function of time for a range of ethane concentration $\left[\mathrm{C}_{2} \mathrm{H}_{6}\right]$ (top) and corresponding loss rates as a function of $\left[\mathrm{C}_{2} \mathrm{H}_{6}\right]$ (bottom), the slope of which determines the rate coefficient of the $\mathrm{O}_{2}{ }^{+}+\mathrm{C}_{2} \mathrm{H}_{6}$ reaction.

In practice, the reaction chamber is first filled with the USF buffer gas in a static manner so that one can optimize the settings of the transfer line without consuming all the gas and power necessary for a CRESU experiment.

A current of several hundreds of $\mathrm{pA}$ was measured on the exit lens and the deflector for chamber pressure $\left(P_{c h}\right)$ of 0.2 to 2.0 mbar, with a maximum at $P_{c h} \sim 1$ mbar. With a de Laval expansion of helium at $49 \mathrm{~K}$ demanding that $P_{c h}=0.77$ mbar, the ion current was monitored on the skimmer at various distances from the exit aperture of the transfer line (from $7 \mathrm{~cm}$ to $20 \mathrm{~cm}$, i.e. the effective length of this uniform flow). Applying a voltage of $30 \pm 1 \mathrm{~V}$ on the deflector allowed for more than $95 \%$ of the selected ions to be drifted towards the skimmer. The measurements showed no variations greater than 3-4\% along the flow. We found that the current is very sensitive to the voltage applied on the deflector as a change of $\pm 5 \mathrm{~V}$ leads to its complete disappearance. This way, a simple yet fine tuning of the kinetic energy necessary for inseminating the USF with the selected ions is achieved.

The ion content of the USF was monitored by the mov-
TABLE I. Rate coefficients $k$ compared with previous measurements and Langevin rates.

\begin{tabular}{|c|c|c|c|c|c|}
\hline & $T(\mathrm{~K})$ & $k(10$ & ${ }^{n}$ molecule ${ }^{-1}$ & $\left.\mathrm{~cm}^{3} \mathrm{~s}^{-1}\right)$ & \\
\hline & & This work & Prev. meas. & Langevin & {$[n]$} \\
\hline $\mathrm{Ar}^{+}+\mathrm{C}_{2} \mathrm{H}_{6}$ & $36^{\mathrm{a}}$ & $1.20 \pm 0.12$ & $0.86^{\mathrm{b}}$ & 1.16 & [-9] \\
\hline & $49^{\mathrm{a}}$ & $1.33 \pm 0.13$ & - & & \\
\hline & 300 & - & $0.92^{\mathrm{c}}$ & & \\
\hline & 380 & - & $1.14^{\mathrm{d}}$ & & \\
\hline $\mathrm{O}_{2}{ }^{+}+\mathrm{C}_{2} \mathrm{H}_{6}$ & $49^{\mathrm{a}}$ & $1.21 \pm 0.13$ & - & 1.22 & {$[-9]$} \\
\hline & 300 & - & $1.21^{\mathrm{e}} / 1.1^{\mathrm{f}}$ & & \\
\hline $\mathrm{Ar}^{+}+\mathrm{N}_{2} \mathrm{O}$ & $36^{\mathrm{a}}$ & $4.6 \pm 0.5$ & - & 8.9 & {$[-10]$} \\
\hline & $49^{\mathrm{a}}$ & $5.7 \pm 0.9$ & - & & \\
\hline & $72^{\mathrm{a}}$ & $4.8 \pm 0.6$ & - & & \\
\hline & 300 & - & $3.3^{\mathrm{g}} / 3.0^{\mathrm{h}}$ & & \\
\hline $\mathrm{Ar}^{+}+\mathrm{N}_{2}$ & $36^{\mathrm{a}}$ & $3.07 \pm 0.27$ & $3.00^{\mathrm{b}}$ & 75.5 & [-11] \\
\hline & $49^{\mathrm{a}}$ & $2.00 \pm 0.19$ & - & & \\
\hline & $72^{\mathrm{a}}$ & $1.09 \pm 0.12$ & $1.30^{\mathrm{b}}$ & & \\
\hline
\end{tabular}

a Flow temperatures $( \pm 1 \mathrm{~K})$ determined by impact pressure and laser-induced fluorescence measurements.

b CRESU with pulsed ion injection by Speck et al. ${ }^{42}$

${ }^{c}$ Flowing afterglow experiments by Tsuji et al. ${ }^{47}$

${ }^{d}$ Selected ion flow drift tube experiments by Praxmarer et al. ${ }^{48}$

e Time-resolved atmospheric pressure ionization mass spectrometry experiments performed in the [238-458] K range by Matsuoka and Ikezoe ${ }^{49}$

${ }^{\mathrm{f}}$ Selected ion flow tube experiments by Wilson et al..$^{50}$

g Selected ion flow tube experiments by Shul et al. ${ }^{51}$

$\mathrm{h}$ Ion cyclotron resonance mass spectrometry experiments by Kemper and Bowers ${ }^{52}$

able QMS incorporating the new ion sampler, as illustrated in Fig. 5 for the $\mathrm{Ar}^{+}+\mathrm{N}_{2} \mathrm{O}$ reaction. $\mathrm{Ar}^{+}$is the only ion detected in absence of $\mathrm{N}_{2} \mathrm{O}$ while the reaction leads to the appearance of the single product $\mathrm{N}_{2} \mathrm{O}^{+}$.

\section{KINETICS AND BRANCHING RATIOS}

The rate coefficients $k$ and branching ratios of a set of benchmark ion-molecule reactions were measured at various temperatures with the new mass-selective transfer line and ion sampling scheme. Kinetic data were obtained under pseudo-first order conditions by measuring the loss rates of the mass-selected ions for various concentrations of neutral co-reactant set in excess, as illustrated in Fig. 6 for the $\mathrm{O}_{2}{ }^{+}+\mathrm{C}_{2} \mathrm{H}_{6}$ reaction. Rate coefficients are compared with previous measurements and Langevin rates in Table I. Error bars account for statistical and systematic $(10 \%)$ contributions, the latter finding its origin in uncertainties in the mass flow rates and the reservoir / chamber pressures. The branching ratios reported in Table II were determined at short reaction times to minimize secondary reactions.

Two exoergic ion-molecule reactions involving $\mathrm{Ar}^{+}$ and $\mathrm{O}_{2}{ }^{+}$with non-polar ethane $\mathrm{C}_{2} \mathrm{H}_{6}$ were studied. For these reactions, $k$ remains constant as a function of temperature. Previous measurements at $300 \mathrm{~K}$ and above have shown a close agreement with Langevin rates, ${ }^{49,53}$ 
TABLE II. Branching ratios for the $\mathrm{Ar}^{+}+\mathrm{C}_{2} \mathrm{H}_{6}$ and $\mathrm{O}_{2}{ }^{+}+$ $\mathrm{C}_{2} \mathrm{H}_{6}$ reactions and comparison with previous measurements.

\begin{tabular}{lcccc}
\hline \hline Products & & \multicolumn{3}{c}{ Branching ratios } \\
& & This work & Prev. & meas. \\
\hline $\mathrm{Ar}^{+}+\mathrm{C}_{2} \mathrm{H}_{6} \rightarrow$ & $T(\mathrm{~K})=$ & 49 & $300^{\mathrm{b}}$ & $380^{\mathrm{c}}$ \\
\hline $\mathrm{C}_{2} \mathrm{H}_{6}{ }^{+}+\mathrm{Ar}$ & 0.03 & - & - \\
$\mathrm{C}_{2} \mathrm{H}_{5}{ }^{+}+\mathrm{H}+\mathrm{Ar}$ & 0.10 & 0.08 & 0.18 \\
$\mathrm{C}_{2} \mathrm{H}_{4}^{+}+\mathrm{H}_{2}+\mathrm{Ar}$ & 0.23 & 0.22 & 0.18 \\
$\mathrm{C}_{2} \mathrm{H}_{3}{ }^{+}+\mathrm{H}_{2}+\mathrm{H}+\mathrm{Ar}$ & 0.36 & 0.42 & 0.38 \\
$\mathrm{C}_{2} \mathrm{H}_{2}{ }^{+}+2 \mathrm{H}_{2}+\mathrm{Ar}$ & & 0.23 & 0.23 & 0.20 \\
$\mathrm{CH}_{3}{ }^{+}+\mathrm{CH}_{3}+\mathrm{Ar}$ & & 0.05 & 0.05 & 0.06 \\
\hline $\mathrm{O}_{2}{ }^{+}+\mathrm{C}_{2} \mathrm{H}_{6} \rightarrow$ & $T(\mathrm{~K})=$ & 49 & $300^{\mathrm{d}}$ & \\
$\mathrm{C}_{2} \mathrm{H}_{6}{ }^{+}+\mathrm{O}_{2}$ & & 0.26 & 0.30 & \\
$\mathrm{C}_{2} \mathrm{H}_{5}{ }^{+}+\mathrm{O}_{2}+\mathrm{H}$ & & 0.57 & 0.55 & \\
$\mathrm{C}_{2} \mathrm{H}_{4}{ }^{+}+\mathrm{O}_{2}+\mathrm{H}_{2}$ & & 0.17 & 0.15 & \\
\hline \hline
\end{tabular}

a Error bars can be estimated by adding systematic $( \pm 0.02)$ and statistical $( \pm 5 \%)$ contributions.

b Flowing afterglow experiments by Tsuji et al. ${ }^{47}$

${ }^{c}$ Selected ion flow drift tube experiments by Praxmarer et al. ${ }^{48}$

d Selected ion flow tube experiments by Wilson et al. ${ }^{50}$

as our new low-temperature results for both reactions. In the case of the $\mathrm{Ar}^{+}+\mathrm{C}_{2} \mathrm{H}_{6}$ reaction, the branching into the six identified exit channels, for which dissociative charge transfer reactions dominate (97\%), agree well with previous flowing afterglow ${ }^{47}$ and selected ion flow drift tube ${ }^{48}$ measurements. In the case of the $\mathrm{O}_{2}{ }^{+}+\mathrm{C}_{2} \mathrm{H}_{6}$ reaction, three exit channels leading to $\mathrm{C}_{2} \mathrm{H}_{6}{ }^{+}$(charge transfer) and $\mathrm{C}_{2} \mathrm{H}_{5}{ }^{+} / \mathrm{C}_{2} \mathrm{H}_{4}{ }^{+}$(dissociative charge transfer) have been reported previously and their branching ratios measured at $300 \mathrm{~K}$ with the SIFT technique. ${ }^{50}$ The results obtained here at $49 \mathrm{~K}$ show a remarkable agreement with the SIFT values, suggesting that the branching of this reaction does not, as for the $\mathrm{Ar}^{+}+\mathrm{C}_{2} \mathrm{H}_{6}$ reaction, depend on temperature over the explored range.

The kinetics of two charge transfer reactions with temperature-dependent rate coefficients was also measured. For the $\mathrm{Ar}^{+}+\mathrm{N}_{2} \mathrm{O}$ reaction, the rate coefficients measured at low temperatures are only slightly higher than the one measured at $300 \mathrm{~K}$ because little temperature dependence is expected due to the small dipole moment of $\mathrm{N}_{2} \mathrm{O}(\mu=0.16 \mathrm{D})$. The new rates reach about $60 \%$ of the Langevin rate, compared to $35 \%$ at $300 \mathrm{~K}$. In contrast, $k$ is much smaller than the Langevin rate for the $\mathrm{Ar}^{+}+\mathrm{N}_{2}(1-4 \%)$ and exhibits a pronounced negative temperature dependence below $140 \mathrm{~K}$ although $\mathrm{N}_{2}$ is non-polar (see Fig. 7). This is due to the competition between two exit channels: $\mathrm{N}_{2}+(v=0)+\mathrm{Ar}$, exoergic by $0.18 \mathrm{eV}$ and dominant at $T<140 \mathrm{~K}$, and $\mathrm{N}_{2}{ }^{+}$ $(v=1)+$ Ar, endoergic by $0.09 \mathrm{eV}$ and dominant at higher temperatures. ${ }^{54}$ The kinetic results are totally consistent with previous SIFT $^{55}$ and CRESU ${ }^{42,56}$ measurements.

Whereas the thermalization of the translational and rotational degrees of freedom is extremely efficient within a uniform supersonic flow owing to its high density the mean time between collisions with the buffer gas is typically a few tenths of nanoseconds -, the relaxation

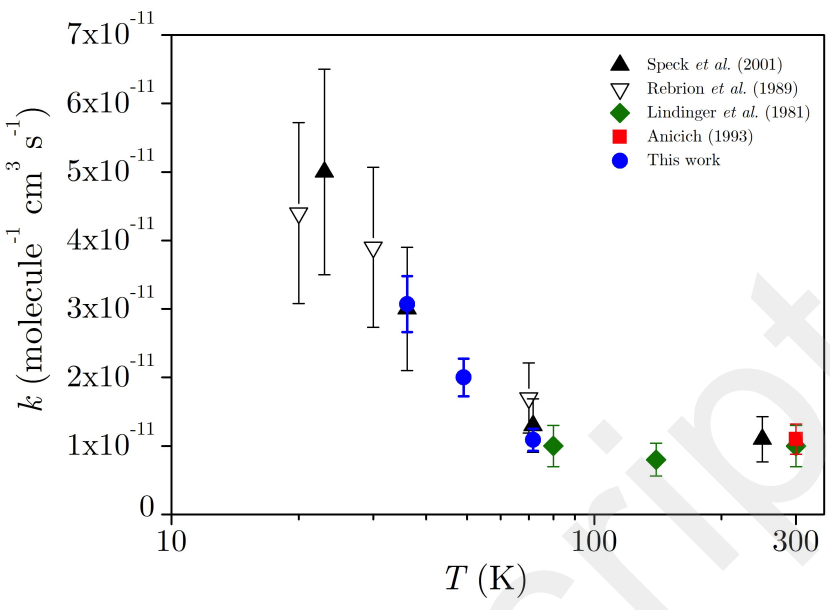

FIG. 7. Rate coefficients for the $\mathrm{Ar}^{+}+\mathrm{N}_{2}$ reaction as a function of temperature. Blue circles: this work. Black triangles: previous CRESU measurements. ${ }^{42,56}$ Green diamonds: SIFT measurements. ${ }^{55}$ Red square: Average room temperature value taken from the review of V.G. Anicich. ${ }^{57}$

of electronic and vibrational excited states of the massselected ions must be taken with caution, alike in SIFT studies. Spin-orbit excited states of $\mathrm{Ar}^{+}$and vibrational excited states of $\mathrm{O}_{2}{ }^{+}$are indeed likely to be formed in the plasma source. According to Hamdan et al. ${ }^{58}$ the de-excitation rate of $\mathrm{Ar}^{+}\left({ }^{2} P_{1 / 2}\right)$ to $\mathrm{Ar}^{+}\left({ }^{2} P_{3 / 2}\right)$ is equal to $\sim 4 \times 10^{-11}$ molecule ${ }^{-1} \mathrm{~cm}^{3} \mathrm{~s}^{-1}$ in $\mathrm{He}$, meaning that the relaxation to the ground state is achieved in the submicrosecond time scale, i.e. directly in the dense plasma source. For molecular ions, vibrational relaxation may turn out to be slow, in particular in the case of nonpolar diatomic molecules with relatively high frequency vibrations. ${ }^{59}$ To settle this debate, the vibrational deactivation of $\mathrm{O}_{2}{ }^{+}(v=1,2)$ with different neutral partners was investigated in the laboratory by Böhringer et al. ${ }^{60}$ Their experiments showed that only $\sim 2$ collisions with neutral $\mathrm{O}_{2}$ are necessary to quench the $v=1$ and $v=2$ states of $\mathrm{O}_{2}^{+}$, making this process very efficient. Ion trajectory simulations with a hard sphere collision model show that $\mathrm{O}_{2}^{+}$ions undergo $\sim 800$ collisions from their production zone to the funnel exit while only a handful of additional collisions take place in the ion guide. By considering a typical mixing ratio of $\mathrm{O}_{2}$ in $\mathrm{He}$ of $1 \%$, we estimate that $\mathrm{O}_{2}^{+}$ions undergo $\sim 8$ collisions with neutral $\mathrm{O}_{2}$ during their travel in the ionization source. This is a conservative number because more sophisticated collision models based on ion mobility data show that the hard sphere model employed here underestimates the collision cross sections for low relative velocities. These simulations therefore suggest that $\mathrm{O}_{2}^{+}$ions are thermalized at the very beginning of the mass-selective ion transfer line. From an experimental viewpoint, the kinetic traces would likely show some curvature in case significant amounts of either spin-orbit excited $\mathrm{Ar}^{+}$or vibrationally excited $\mathrm{O}_{2}^{+}$ ions were injected. ${ }^{61}$ For instance, the effect of vibrational excitation of $\mathrm{O}_{2}^{+}$on the rate coefficient of the charge ex- 
change reaction $\mathrm{O}_{2}^{+}+\mathrm{O}_{2}$ has been shown to enhance the reactivity. ${ }^{62}$ Here the rate coefficients and branching ratios show overall a good agreement with previous work, providing additional evidence for the effective thermalization of the selected ions inseminating the de Laval expansion. We can therefore consider that no excited states of either $\mathrm{Ar}^{+}$or $\mathrm{O}_{2}^{+}$were interfering with the kinetic measurements.

The ultimate goal of the apparatus presented here remains the investigation of reactions with large polyatomic ions. Ferguson and coworkers pointed out that vibrational deactivation efficiency is greater for low frequency vibrations, in which a lesser amount of vibrational energy need to be converted into translational energy. ${ }^{59}$ As their neutral precursors will be injected in significant amounts $(\sim 1 \%)$ in the source, one can very reasonably assume that polyatomic ions will efficiently relax in the plasma chamber itself, leaving little doubt on their good thermalization. Hence, the ion transfer line offers the convenience of preparing mass-selected, ground state ions remotely, restraining the introduction in the uniform supersonic flow of the species of interest only and permitting a simple, robust analysis of low-temperature multichannel kinetic data. Depending on the studied ions, these results do not however preclude for additional spectroscopic measurements to assess the internal energy of ions but common sensitive methods (e.g. laser-induced fluorescence or cavity ring-down spectroscopy) are vain considering the very low density of ions in the flow, leaving only indirect methods such as action spectroscopy.

\section{CONCLUSION AND PERSPECTIVES}

The new experimental approach presented here - a mass-selective ion transfer line coupled with the uniform supersonic flow technique to measure rate coefficients and branching ratios of ion-molecule reactions at low temperatures - allows for monitoring this class of reactions in a thermalized medium where no condensation takes place and where only the target species are present. The data analysis is made straightforward and the same versatility than the selected ion flow tube technique has been demonstrated while offering new possibilities for investigating ion-molecule reactions in the cold regime. The design of the ion transfer line, which takes advantage of the relatively high pressure in the reaction chamber and of the combination of quadrupolar and octapolar radio frequency field orders, makes possible to concurrently (i) maximize ion transmission through large pressure gradients, (ii) ensure the prompt thermalization of the massselected ions, (iii) redirect the ion cloud along the propagation axis of the cold de Laval expansion readily. Provided an efficient ionization source, this new strategy will be dedicated to unveil the low-temperature reactivity of polyatomic ions of astrophysical interest, e.g. $\mathrm{H}-$ $(\mathrm{C} \equiv \mathrm{C})_{n}{ }^{-}$polyynes, and molecular clusters such as microsolvated ions.
The current apparatus is restricted to $\mathrm{He} / \mathrm{H}_{2}$ uniform supersonic flows because of significant scattering occurring in the injection region. To overcome this limitation, the design of low-density, low-pressure nozzles is underway. A better control over the pressure in the second, elongated ion guide with additional pumping capacity would be also advantageous. Alternatively, the development of a differential aperture with an adjustable diameter - an iris diaphragm for ion optics - to be mounted at the interface between the ion transfer line and the reaction chamber would facilitate the control of the balance between ion transmission, collisional focusing, and scattering over the diversity of conditions imposed by the fluid dynamics of de Laval expansions. Although the present version of the mass-selective ion transfer line has not been designed initially to be coupled with pulsed CRESU flows, we anticipate that this would not require any major adjustment. In both ways - continuous and pulsed - the sensitivity of the detection could be further enhanced by maintaining a higher vacuum in the hexapole ion guide linking the molecular beam skimmer to the entry lens of the quadrupole mass spectrometer.

\section{ACKNOWLEDGMENT}

We thank J. Courbe for the mechanical adaptation and J. Thiévin for the data acquisition. We are also grateful to the referees for their valuable comments. This work was supported by the Agence Nationale de la Recherche through the AnionCosChem project (ANR-14CE33-0013) and the national research programs Physique et Chimie du Milieu Interstellaire (PCMI) and Programme National de Planétologie (PNP) of CNRS/INSU with INC/INP and co-funded by CEA and CNES.

\footnotetext{
${ }^{1}$ S. Petrie and D. K. Bohme, "Ions in space," Mass Spectrometry Reviews 26, 258-280 (2007).

${ }^{2}$ T. P. Snow and V. M. Bierbaum, "Ion chemistry in the interstellar medium," Annual Review of Analytical Chemistry 1, 229-259 (2008).

${ }^{3}$ M. Larsson, W. D. Geppert, and G. Nyman, "Ion chemistry in space," Reports on Progress in Physics 75, 066901 (2012).

${ }^{4}$ T. J. Millar, C. Walsh, and T. A. Field, "Negative ions in space," Chemical Reviews 117, 1765-1795 (2017).

${ }^{5}$ M. McCarthy, C. Gottlieb, H. Gupta, and P. Thaddeus, "Laboratory and astronomical identification of the negative molecular ion $\mathrm{C}_{6} \mathrm{H}^{-}, "$ Astrophys. J. Lett. 652, L141 (2006).

${ }^{6}$ J. Cernicharo, M. Guélin, M. Agúndez, K. Kawaguchi, M. McCarthy, and P. Thaddeus, "Astronomical detection of $\mathrm{C}_{4} \mathrm{H}^{-}$, the second interstellar anion," Astronony \& Astrophysics 467, L37-L40 (2007).

${ }^{7}$ S. Brünken, H. Gupta, C. Gottlieb, M. McCarthy, and P. Thaddeus, "Detection of the carbon chain negative ion $\mathrm{C}_{8} \mathrm{H}^{-}$in TMC1," Astrophysical Journal Letters 664, L43 (2007).

${ }^{8}$ P. Thaddeus, C. Gottlieb, H. Gupta, S. Brünken, M. McCarthy, M. Agúndez, M. Guélin, and J. Cernicharo, "Laboratory and astronomical detection of the negative molecular ion $\mathrm{C}_{3} \mathrm{~N}^{-}$," Astrophys. J. 677, 1132 (2008).

${ }^{9}$ J. Cernicharo, M. Guélin, M. Agúndez, M. McCarthy, and P. Thaddeus, "Detection of $\mathrm{C}_{5} \mathrm{~N}^{-}$and vibrationally excited $\mathrm{C}_{6} \mathrm{H}$ in IRC+10216," Astrophysical Journal Letters 688, L83 (2008).
} 
${ }^{10}$ M. Agúndez, J. Cernicharo, M. Guélin, C. Kahane, E. Roueff, J. Kłos, F. Aoiz, F. Lique, N. Marcelino, J. Goicoechea, et al., "Astronomical identification of $\mathrm{CN}^{-}$, the smallest observed molecular anion," Astron. \& Astrophys. 517, L2 (2010).

${ }^{11}$ E. Herbst and E. F. van Dishoeck, "Complex organic interstellar molecules," Annual Review of Astronomy and Astrophysics 47, 427-480 (2009)

12 J. H. Waite, D. T. Young, T. E. Cravens, A. J. Coates, F. J. Crary, B. Magee, and J. Westlake, "The process of tholin formation in Titan's upper atmosphere," Science 316, 870 (2007).

${ }^{13}$ F. J. Crary, B. A. Magee, K. Mandt, J. H. Waite Jr, J. Westlake, and D. T. Young, "Heavy ions, temperatures and winds in Titan's ionosphere: Combined Cassini CAPS and INMS observations," Planetary and Space Science 57, 1847-1856 (2009).

${ }^{14}$ A. J. Coates, F. J. Crary, G. R. Lewis, D. T. Young, J. H. Waite, and E. C. Sittler, "Discovery of heavy negative ions in Titan's ionosphere," Geophysical Research Letters 34, L22103 (2007).

${ }^{15} \mathrm{~J}$. Žabka, C. Romanzin, C. Alcaraz, and M. Polášek, "Anion chemistry on titan: A possible route to large N-bearing hydrocarbons," Icarus 219, 161-167 (2012).

${ }^{16}$ P. Lavvas, R. V. Yelle, T. Koskinen, A. Bazin, V. Vuitton, E. Vigren, M. Galand, A. Wellbrock, A. J. Coates, J.-E. Wahlund, F. J. Crary, and D. Snowden, "Aerosol growth in Titan's ionosphere," Proceedings of the National Academy of Sciences (2013).

${ }^{17}$ D. Gerlich, "Ion-neutral collisions in a $22-$ pole trap at very low energies," Physica Scripta 1995, 256 (1995).

${ }^{18}$ S. Barlow, G. Dunn, and M. Schauer, "Radiative association of $\mathrm{CH}_{3}{ }^{+}$and $\mathrm{H}_{2}$ at $13 \mathrm{~K}$," Physical Review Letters 52, 902 (1984).

${ }^{19}$ D. Gerlich and G. Kaefer, "Ion trap studies of association processes in collisions of $\mathrm{CH}_{3}{ }^{+}$and $\mathrm{CD}_{3}{ }^{+}$with $n-\mathrm{H}_{2}, p-\mathrm{H}_{2}, \mathrm{D}_{2}$, and $\mathrm{He}$ at $80 \mathrm{~K}$," The Astrophysical Journal 347, 849-854 (1989).

${ }^{20}$ R. Otto, J. Mikosch, S. Trippel, M. Weidemüller, and R. Wester, "Nonstandard behavior of a negative ion reaction at very low temperatures," Physical Review Letters 101, 063201 (2008).

${ }^{21} \mathrm{~S}$. Willitsch, M. T. Bell, A. D. Gingell, S. R. Procter, and T. P. Softley, "Cold reactive collisions between laser-cooled ions and velocity-selected neutral molecules," Physical Review Letters 100, 043203 (2008).

${ }^{22}$ B. R. Heazlewood and T. P. Softley, "Low-temperature kinetics and dynamics with Coulomb crystals," Annual Review of Physical Chemistry 66, 475-495 (2015).

${ }^{23}$ J. Greenberg, P. C. Schmid, M. Miller, J. F. Stanton, and H. Lewandowski, "Quantum-state-controlled reactions between molecular radicals and ions," Physical Review A 98, 032702 (2018).

${ }^{24}$ T. Yang, A. Li, G. K. Chen, C. Xie, A. G. Suits, W. C. Campbell, H. Guo, and E. R. Hudson, "Optical control of reactions between water and laser-cooled $\mathrm{Be}^{+}$ions," The Journal of Physical Chemistry Letters (2018).

${ }^{25} \mathrm{~B}$. R. Rowe and J. B. Marquette, "CRESU studies of ionmolecule reactions," International Journal of Mass Spectrometry and Ion Processes 80, 239-254 (1987).

${ }^{26}$ I. Sims, J.-L. Queffelec, A. Defrance, C. Rebrion-Rowe, D. Travers, P. Bocherel, B. Rowe, and I. W. Smith, "Ultralow temperature kinetics of neutral-neutral reactions. the technique and results for the reactions $\mathrm{CN}+\mathrm{O}_{2}$ down to $13 \mathrm{k}$ and $\mathrm{CN}$ $+\mathrm{NH}_{3}$ down to $25 \mathrm{k}$," The Journal of chemical physics 100, 4229-4241 (1994).

${ }^{27}$ S. Lee, R. J. Hoobler, and S. R. Leone, "A pulsed laval nozzle apparatus with laser ionization mass spectroscopy for direct measurements of rate coefficients at low temperatures with condensable gases," Review of Scientific Instruments 71, 1816-1823 (2000)

${ }^{28}$ A. Bonnamy, R. Georges, E. Hugo, and R. Signorell, "Ir signature of $\left(\mathrm{CO}_{2}\right)_{n}$ clusters: size, shape and structural effects," Physical Chemistry Chemical Physics 7, 963-969 (2005).

${ }^{29}$ H. Sabbah, L. Biennier, S. J. Klippenstein, I. R. Sims, and B. R. Rowe, "Exploring the role of PAHs in the formation of soot: Pyrene dimerization," The Journal of Physical Chemistry
Letters 1, 2962-2967 (2010).

${ }^{30}$ S. Soorkia, C.-L. Liu, J. D. Savee, S. J. Ferrell, S. R. Leone, and K. R. Wilson, "Airfoil sampling of a pulsed laval beam with tunable vacuum ultraviolet synchrotron ionization quadrupole mass spectrometry: Application to low-temperature kinetics and product detection," Review of Scientific Instruments 82, 124102 (2011).

${ }^{31}$ C. Abeysekera, B. Joalland, N. Ariyasingha, L. N. Zack, I. R. Sims, R. W. Field, and A. G. Suits, "Product branching in the low temperature reaction of $\mathrm{CN}$ with propyne by chirpedpulse microwave spectroscopy in a uniform supersonic flow," The journal of physical chemistry letters 6, 1599-1604 (2015).

${ }^{32}$ B. Schläppi, J. H. Litman, J. J. Ferreiro, D. Stapfer, and R. Signorell, "A pulsed uniform laval expansion coupled with single photon ionization and mass spectrometric detection for the study of large molecular aggregates," Physical Chemistry Chemical Physics 17, 25761-25771 (2015)

${ }^{33}$ D. B. Atkinson and M. A. Smith, "Design and characterization of pulsed uniform supersonic expansions for chemical applications," Review of scientific instruments 66, 4434-4446 (1995).

${ }^{34}$ J. M. Oldham, C. Abeysekera, B. Joalland, L. N. Zack, K. Prozument, I. R. Sims, G. B. Park, R. W. Field, and A. G. Suits, "A chirped-pulse fourier-transform microwave/pulsed uniform flow spectrometer. i. the low-temperature flow system," The Journal of chemical physics 141, 154202 (2014).

${ }^{35}$ E. Jiménez, B. Ballesteros, A. Canosa, T. Townsend, F. Maigler, V. Napal, B. Rowe, and J. Albaladejo, "Development of a pulsed uniform supersonic gas expansion system based on an aerodynamic chopper for gas phase reaction kinetic studies at ultralow temperatures," Review of Scientific Instruments 86, 045108 (2015).

${ }^{36}$ A. Canosa, A. Ocaña, M. Antinolo, B. Ballesteros, E. Jiménez, and J. Albaladejo, "Design and testing of temperature tunable de laval nozzles for applications in gas-phase reaction kinetics," Experiments in Fluids 57, 152 (2016).

${ }^{37}$ L. Biennier, S. Carles, D. Cordier, J.-C. Guillemin, S. D. Le Picard, and A. Faure, "Low temperature reaction kinetics of $\mathrm{CN}^{-}$ $+\mathrm{HC}_{3} \mathrm{~N}$ and implications for the growth of anions in Titan's atmosphere," Icarus 227, 123-131 (2014).

${ }^{38}$ J. Bourgalais, N. Jamal-Eddine, B. Joalland, M. Capron, M. Balaganesh, J.-C. Guillemin, S. D. Le Picard, A. Faure, S. Carles, and L. Biennier, "Elusive anion growth in Titan's atmosphere: Low-temperature kinetics of the $\mathrm{C}_{3} \mathrm{~N}^{-}+\mathrm{HC}_{3} \mathrm{~N}$ reaction," Icarus 271, 194-201 (2016).

${ }^{39}$ B. Joalland, N. Jamal-Eddine, J. Klos, F. Lique, Y. Trolez, J.C. Guillemin, S. Carles, and L. Biennier, "Low-temperature reactivity of $\mathrm{C}_{2 n+1} \mathrm{~N}^{-}$anions with polar molecules," Journal of Physical Chemistry Letters 7, 2957-2961 (2016).

${ }^{40}$ J.-L. Le Garrec, B. Rowe, J. L. Queffelec, J. B. A. Mitchell, and D. C. Clary, "Temperature dependence of the rate constant for the $\mathrm{Cl}^{-}+\mathrm{CH}_{3} \mathrm{Br}$ reaction down to $23 \mathrm{~K}$," Journal of Chemical Physics 107, 1021-1024 (1997).

${ }^{41}$ D. Smith and N. Adams, "The selected ion flow tube (sift): Studies of ion-neutral reactions," in Advances in Atomic and Molecular Physics, Vol. 24 (Elsevier, 1988) pp. 1-49.

${ }^{42}$ T. Speck, T. I. Mostefaoui, D. Travers, and B. R. Rowe, "Pulsed injection of ions into the CRESU experiment," International Journal of Mass Spectrometry 208, 73-80 (2001).

${ }^{43}$ D. Douglas and J. B. French, "Collisional focusing effects in radio frequency quadrupoles," Journal of the American Society for Mass Spectrometry 3, 398-408 (1992).

${ }^{44}$ More details regarding the rf ion guide combining different fieldorder distributions can be found in patent US9123517(B2).

${ }^{45}$ G. A. Bird, "Molecular gas dynamics," NASA STI/Recon Technical Report A 76 (1976)

${ }^{46}$ D. Papanastasiou, A. Lekkas, E. Raptakis, and M. Sudakov, "Simulation of ion mobility and diffusion of sodium ions based on revised ion-molecule collision models," in Proceedings of the $60^{\text {th }}$ ASMS Conference on Mass Spectrometry and Allied Topics (American Society for Mass Spectrometry, 2012). 
${ }^{47}$ M. Tsuji, H. Kouno, K. Matsumura, T. Funatsu, Y. Nishimura, H. Obase, H. Kugishima, and K. Yoshida, "Dissociative chargetransfer reactions of $\mathrm{Ar}^{+}$with simple aliphatic hydrocarbons at thermal energy," The Journal of Chemical Physics 98, 2011-2022 (1993).

${ }^{48}$ C. Praxmarer, A. Hansel, W. Lindinger, and Z. Herman, "A selected-ion-flow-drift-tube study of charge transfer processes between atomic, molecular, and dimer ion projectiles and polyatomic molecules ethane, propane, and $n$-butane," The Journal of Chemical Physics 109, 4246-4251 (1998).

${ }^{49} \mathrm{~S}$. Matsuoka and Y. Ikezoe, "Ion-molecule reactions and thermal decomposition of ions in nitrogen-oxygen alkane $(\mathrm{C} 2-\mathrm{C} 8)$ mixtures studied by time-resolved atmospheric pressure ionization mass spectrometry," The Journal of Physical Chemistry 92, 1126-1133 (1988).

${ }^{50}$ P. F. Wilson, C. G. Freeman, and M. J. McEwan, "Reactions of small hydrocarbons with $\mathrm{H}_{3} \mathrm{O}^{+}, \mathrm{O}_{2}+$ and $\mathrm{NO}^{+}$ions," International Journal of Mass Spectrometry 229, 143-149 (2003).

${ }^{51}$ R. J. Shul, B. L. Upschulte, R. Passarella, R. G. Keesee, and A. W. Castleman, "Thermal energy charge-transfer reactions of argon ions $\left(\mathrm{Ar}^{+}\right.$and $\left.\mathrm{Ar}_{2}^{+}\right)$," The Journal of Physical Chemistry 91, 2556-2562 (1987).

${ }^{52} \mathrm{P}$. R. Kemper and M. T. Bowers, "An improved tandem mass spectrometer - ion cyclotron resonance spectrometer," International journal of mass spectrometry and ion physics 52, 1-24 (1983).

${ }^{53}$ H. Chatham, D. Hils, R. Robertson, and A. Gallagher, "Reactions of $\mathrm{He}^{+}, \mathrm{Ne}^{+}$, and $\mathrm{Ar}^{+}$with $\mathrm{CH}_{4}, \mathrm{C}_{2} \mathrm{H}_{6}, \mathrm{SiH}_{4}$, and $\mathrm{Si}_{2} \mathrm{H}_{6}$," The Journal of chemical physics 79, 1301-1311 (1983).

${ }^{54}$ D. Smith and N. Adams, "Charge-transfer reaction $\mathrm{Ar}^{+}+\mathrm{N}_{2}$ $\rightleftharpoons \mathrm{N}_{2}{ }^{+}+$Ar at thermal energies," Physical Review A 23, 2327
(1981).

${ }^{55}$ W. Lindinger, F. Howorka, P. Lukac, S. Kuhn, H. Villinger, E. Alge, and H. Ramler, "Charge-transfer reaction $\mathrm{Ar}^{+}+\mathrm{N}_{2}$ $\rightleftharpoons \mathrm{N}_{2}{ }^{+}+$Ar at near thermal energies," Physical Review A 23, 2319 (1981)

${ }^{56}$ C. Rebrion, B. Rowe, and J. Marquette, "Reactions of $\mathrm{Ar}^{+}$ with $\mathrm{H}_{2}, \mathrm{~N}_{2}, \mathrm{O}_{2}$, and $\mathrm{CO}$ at 20,30 , and $70 \mathrm{~K}$," The Journal of Chemical Physics 91, 6142-6147 (1989).

${ }^{57}$ V. G. Anicich, "Evaluated bimolecular ion-molecule gas phase kinetics of positive ions for use in modeling planetary atmospheres, cometary comae, and interstellar clouds," Journal of Physical and Chemical Reference Data 22, 1469-1569 (1993).

${ }^{58}$ M. Hamdan, K. Birkinshaw, and N. Twiddy, "Energy dependence of the reactions of $\mathrm{Ar}^{+}\left({ }^{2} P_{1 / 2}\right)$ and $\mathrm{Ar}^{+}\left({ }^{2} P_{3 / 2}\right)$ with $\mathrm{N}_{2}$," International Journal of Mass Spectrometry and Ion Processes 57, 225-231 (1984).

${ }^{59}$ E. E. Ferguson, "Vibrational quenching of small molecular ions in neutral collisions," The Journal of Physical Chemistry 90, 731-738 (1986).

${ }^{60}$ H. Böhringer, M. Durup-Ferguson, D. Fahey, F. Fehsenfeld, and E. Ferguson, "Collisional relaxation of vibrationally excited $\mathrm{O}_{2}{ }^{+}$ ions," The Journal of Chemical Physics 79, 4201-4213 (1983).

${ }^{61}$ A. A. Viggiano and R. A. Morris, "Rotational and vibrational energy effects on ion-molecule reactivity as studied by the VTSIFDT technique," The Journal of Physical Chemistry 100, 19227-19240 (1996).

${ }^{62}$ R. Derai, P. R. Kemper, and M. T. Bowers, "Effect of reactant ion internal and translational energy on the rate constants of the charge exchange reactions: $\mathrm{CO}_{2}^{+}+\mathrm{O}_{2} \rightarrow \mathrm{O}_{2}^{+}+\mathrm{CO}_{2}$ and $\mathrm{O}_{2}^{+}+\mathrm{O}_{2}$ $\rightarrow \mathrm{O}_{2}+\mathrm{O}_{2}^{+}$," The Journal of Chemical Physics 82, 4517-4523 (1985). 